\title{
RESIDÊNCIA PEDAGÓGICA: PRÁTICAS QUE TRANSFORMAM
}

\author{
Pedagogical Residence: Transforming Practices \\ Residencia Pedagógica: Prácticas Transformadoras
}

\section{Resafios}

\section{Miliane Moreira Cardoso Vieira ${ }^{1}$, Alicia de Sousa Santos ${ }^{2}$, Lauana Oliveira Dias ${ }^{3}$, Jaiara Martins Aguiar Monteiro ${ }^{4}$.}

${ }^{1}$ Docente do Curso de Graduação em Letras - Língua Inglesa e Literaturas, Universidade Federal do Tocantins UFT, Araguaína, Tocantins, Brasil.

${ }^{2}$ Graduanda do Curso de Graduação em Letras - Língua Inglesa e Literaturas, Universidade Federal do Tocantins, Araguaína, Tocantins, Brasil.

${ }^{3}$ Graduanda do Curso de Graduação em Letras - Língua Inglesa e Literaturas, Universidade Federal do Tocantins, Araguaína, Tocantins, Brasil.

${ }^{4}$ Professora da Educação Básica, Secretaria de Estado da Educação, Juventude e Esportes do Tocantins - SEDUC, Araguaína, Tocantins, Brasil.

\section{Artigo recebido em 01/04/2020 aprovado em 20/04/2020 publicado em 20/04/2020.}

\section{INTRODUÇÃO}

O presente artigo tem como objetivo trazer à luz as experiências vividas durante o Programa Residência Pedagógica (PRP). Enfatizando as práticas positivas e o que nos foi agregado durante esse tempo, como graduandas de Letras/Língua Inglesa. Durante o curso de Letras temos a etapa de estágio supervisionado, iniciando no quinto período até o fim do curso, que para muitos é uma etapa muito importante, pois é onde o aluno consegue de fato presenciar o trabalho do professor e seu dia a dia. Porém, há muitos detalhes existentes na prática docente que só são percebidos através da experiência própria. Detalhes cruciais na maneira de lecionar, que apenas um programa como o Residência Pedagógica permite desvelar.

Será, portanto, o foco inicial do presente artigo, elucidar as práticas adotadas durante nossa jornada como residentes, e o que isso nos trouxe de benefício para o Ensino de Língua Inglesa (LI). A RP nos permitiu realizar o trabalho do professor em sala de aula, nas escolas onde estávamos durante a residência, enquanto a professora responsável pelas turmas apenas acompanhava, orientando as atividades e metodologias. Portanto, a professora preceptora, que contava com a supervisão da professora supervisora da Universidade, e também com o apoio da direção da escola, apoio esse que também fez total diferença na realização desse trabalho. A nós foi designado o trabalho de lecionar as aulas de Língua Inglesa três a duas vezes por semana, a depender do horário escolar, como também planejar aulas e atualizar o diário do Sistema de Gerenciamento Escolar (SGE), onde são registradas todas as informações dos alunos e das aulas realizadas.

\section{METODOLOGIAS E MATERIAIS}

Nosso foco principal era ministrar aulas diversificadas, pois queríamos que os alunos aprendessem de uma maneira divertida e que eles vissem a Língua Inglesa com outra visão. Já que de acordo com as aulas que havíamos ministrado, todos eles viam o idioma como algo aterrorizante ou muito difícil, então desta vez queríamos fazer algo 
diferente. Pois a nós também foi passada essa ideia durante o ensino básico, em que pensamos que aprender inglês fosse algo muito difícil e inacessível.

Estávamos nesse último período de regências, lecionando em turmas de Ensino Fundamental e Médio, foi possível notar uma grande diferença em questão de abordagens. No primeiro, precisávamos focar em atividades que prendessem total atenção dos alunos, pois como eram mais novos, costumavam ser mais inquietos. O contexto de sala de aula no Ensino Fundamental também é diferente em questões de práticas de aprendizado, como, reading, writing, listening and speaking. No entanto, ao invés de fazer apenas uma atividade para cada habilidade, como no Ensino Médio, precisávamos focar em um mesmo assunto utilizando uma mesma habilidade várias vezes. Já que os alunos eram crianças e pré adolescentes, estes tinham uma capacidade de perder a atenção e foco das aulas muito facilmente. Além disso, não conseguiam fazer associações de uma aula para outra, mesmo que a quantidade de aulas por semana não fossem o suficiente para internalizar o conhecimento do conteúdo. Com esses alunos tínhamos a prática de reciclar os assuntos das aulas anteriores, acrescentando novas informações, como subir uma escada letamente.

Sempre trazendo lições em forma de brincadeiras ou competições, para que fosse possível obter a atenção dos alunos. Tudo que fosse divertido para eles era mais produtivo do que o que julgavam monótono. A partir dessas práticas foi possível então realizar dois eventos na escola envolvendo tais atividades, como, o festival de música e a gincana de Inglês. Envolvendo não só o Ensino Fundamental como também o Médio, trazendo um foco diferente para disciplina, onde os alunos passaram a se sentir mais a vontade e seguros com o aprendizado da Língua Inglesa. Foi principalmente por esses motivos que percebemos uma melhora em ambas as turmas, iniciais e finais, pois os alunos passaram a participar mais, produzir e dar melhores resultados. Acontecimentos esses, que não foram observados nos bimestres anteriores. Agora nesse fechamento fomos capazes de adquirir mais experiência a partir da prática, e testando todas as técnicas até que chegássemos a esse belo resultado.

\section{RESULTADOS E DISCUSSÃO}

Com isso, vemos que a principal necessidade da educação é a formação humana, que recai principalmente sobre os professores, para que ocorra a formação de criticidade dos alunos em sala de aula. Para que possam então enfrentar o mundo e suas complexidades, para que isso aconteça é necessário também que os professores tenham um bom treinamento contínuo, para melhorar e atualizar suas práticas. Depois de criar um bom relacionamento com os alunos, as aulas se tornaram mais interativas, e tivemos mais liberdade para conversar com eles.

Para nós as regências do Ensino Fundamental e Médio, puderam nos mostrar que, a melhor maneira de ensinar é utilizando interdisciplinaridade nas aulas. É perceptível a diferença entre aulas que são mais no quadro para aulas que exigem uma dinâmica entre assuntos variados e não só relacionados à língua. Como por exemplo, estudar ciências em um texto em LI que fala sobre as vitaminas presentes nos vegetais, trazendo mitos e verdades sobre saúde ao consumir certos alimentos. São sobre novas práticas de lecionar, que vínhamos discutindo em sala de aula na Universidade, ao estudar os textos e documentos que servem de referencial para educação e as formas de ensino, para tanto vale ressaltar a fala de Castro (2004):

[...] o processo de transformação de contextos de cursos de Letras justifica-se 
pelo fato de que, tradicionalmente, o modelo de formação aí predominante, embasa-se na racionalidade técnica (Schön, 1987), isto é, na aceitação e na aplicação de verdades únicas. De maneira geral, isso não possibilita aos futuros professores de inglês, alunos nesses contextos, aprender a compreender e a atuar nas complexas e singularidades situações de ensinoaprendizagem que caracterizam as práticas sociais escolares em seus diferentes contextos, e a tomar decisões instrucionais informadas, adequadas às necessidades do momento. (CASTRO, 2004. p, 106)

Para tanto, somos nós alunos da Universidade, que devemos buscar novas formas de mediar o ensino para nossas futuras turmas. Saindo um pouco do tradicional, buscando o auxílio de nossos professores orientadores, com o objetivo de conhecer o contexto dos nossos futuros alunos. Seguindo a singularidade de cada classe e trazendo soluções que vão favorecer o ensino-aprendizagem nesse processo de ensinar LI.

Reavaliando todo o conhecimento adquirido nas regências e observações da Residência Pedagógica no Ensino Médio, é possível notar o quanto foi necessário e relevante. Aprender sobre as dificuldades do Ensino Médio e entender a diferença entre alunos de anos iniciais para alunos de anos finais, pois estes procuram o aprimoramento, almejando uma futura graduação. Mesmo que haja uma minoria na qual os comportamentos e atitudes se igualam aos do Ensino Fundamental.

\section{CONCLUSÃO}

Portanto, chegamos a conclusão que um trabalho distinto ao estágio obrigatório comum, que foi capaz de trazer a nós um novo olhar além da teoria, que nos é passado durante as aulas na Universidade. O que para nós era visto como um grande desafio, hoje, após a experiência da RP, se torna mais que um privilégio. Lecionar e ter vivenciado todo o trabalho docente junto à escola, com turmas de Ensino Fundamental e Médio, mostrou como esse é um trabalho que eleva a capacidade de ser professor. Além de tudo, a RP nos ajudou a ter um bom repertório pedagógico, e a não se sentir deslocado em um primeiro emprego.

\section{AGRADECIMENTO}

Agradecemos a CAPES/PRP, a nossa Professora orientadora Dra. Miliane Moreira Cardoso Vieira, que nos deu a oportunidade de conhecer o programa Residência Pedagógica, e por sempre nos disponibilizar toda a orientação possível durante nossa jornada como graduandas de Letras na Universidade Federal do Tocantins. Agradecemos também a nossa querida preceptora da unidade escolar onde fomos acolhidas, Jaiara Martins, por todos os conselhos dados e os momentos a nós dedicados, somos gratas.

Todos os autores declararam não haver qualquer potencial conflito de interesses referente a este artigo.

\section{REFERÊNCIAS}

BRASIL. Parâmetros Curriculares Nacionais. Linguagens, Códigos e suas tecnologias. Brasília: MEC, 2000. 
Ministério da Educação (MEC), Secretaria de Educação Média e Tecnológica (Semtec). PCN + Ensino médio: orientações educacionais complementares aos Parâmetros Curriculares Nacionais - Linguagens, códigos e suas tecnologias. Brasília: MEC, 2002.

$$
\text { Ministério da Educação (MEC). Base }
$$

Nacional Comum Curricular - Ensino Médio. Brasília: MEC, 2017.
CASTRO, Solange T. Ricardo de. A Linguagem e a Reconstrução da ação docente: um estudo com professoras de inglês de um curso de Letras. In: MAGAlHÃeS, Maria Cecília C. A formação do Professor como um Profissional Crítico: linguagem e reflexão. Campinas, SP: Mercado das Letras, 2009, p.105-118.

TOCANTINS. Secretaria da Educação, Juventude e Esportes. Documento referencial para elaboração dos Planos de Ensino. Palmas: SEDUC, 2018. 